\title{
Aging without becoming old: myth or reality?
}
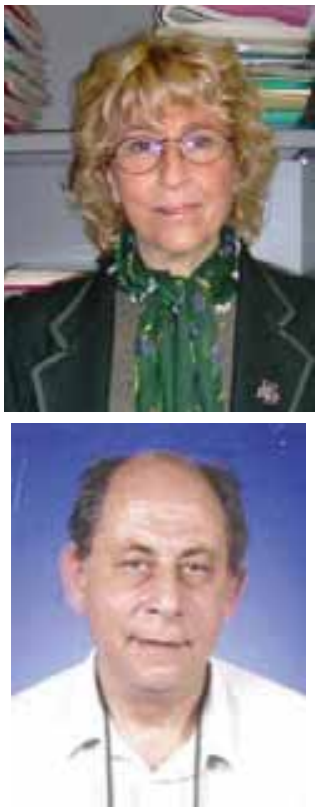

Emine Meral Inelmen ${ }^{1 \dagger}$ \& Erol Inelmen ${ }^{2}$

${ }^{\dagger}$ Author for correspondence 1 U niversity of Padua, D epartment of M edical and Surgical Sciences, Geriatric Section, Clinica Geriatrica - 0 spedale Giustinianeo (2 piano), via Giustiniani 2, 35128, Padova, Italy

Tel.: +39 498212 170; Fax: +39 498211218 ;

E-mail: eminemeral.inelmen @unipd.it

2Bogazici University, School of Applied Sciences, Bebek, Turkey

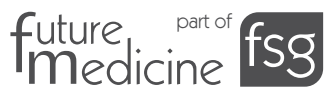

'Although there are numerous definitions of aging, we can agree that aging is prima rily an individual experience, influenced by numerous intrinsic and extrinsic factors.'

The marked increase in life expectancy witnessed in the last few decades has turned the topic of aging into an extremely important issue. Consequently, priority should be given in the future to developing the new framework needed for a 'successful aging' research program. This article focuses on finding evidence for the real meaning of successful aging in the conviction that it is important to thoroughly discuss the related issues and recommend new policies to implement in public-health circles. To this end, we provide some indicators on how to age without growing old.

Wewould all agree that 'aging' is becoming an increasingly important issue for policy makers all over the world. Unfortunately, nothing can be done to delay, stop or reverse the human aging process [1], despite the promise of anti-aging products (intended to make us look younger) that may well succeed in changing our appearance, but do not change our chronological age. In order to provide recommendations on healthy aging for healthcare professionals, we first need to answer some relevant questions. For instance:

-W hat do aging and being old really mean?

- Is it possible to live to be 120 years and still be healthy?

- Is being healthy synonymous with succesfful aging?

- Can we say that healthy aging is the same as succesful aging?

- What exactly do we mean by successful aging? This may not be the whole list of the issues that need to be considered. N evertheless, encouraged by previous work on the subject [2], in the following sections we attempt to provide some answers to these crucial questions. The implementation of these new practices will no doubt depend on the good will of government, healthcare professionals and, of course, the target population. As a guideline, a list of recommendations is given in the Appendix

What do aging \& being old really mean?

Partly because of the remarkable increase in life expectancy emerging in the last few decades, aging and the associated declining ability to work have become an extremely important policy issue. See, for instance, the study on the cardiovascular status of carriers of the apolipoprotein, involving the inhabitants of Limone sul $\mathrm{G}$ arda in N orthern Italy, whose long and healthy life has been studied in depth [3].

What we know for sure about aging is that everyone unavoidably grows older every day, and death awaits us all at the end of our journey. As we grow old we realize, maybe for the first time, that we are not immortal. Although there are numerous definitions of aging, we can agree that aging is primarily an individual experience, influenced by numerous intrinsic and extrinsic factors.

Everybody ages according to their personal lifestyle and behavior, and the scenario varies: an 80-year-old may still work and seem to be only 50 years old, while a 50 -year-old may be wheelchair-bound and seem to be aged 80 years. So how can aging be given a standard definition? Since the elderly population is very heterogeneous, instead of 'old' or 'elderly', the term 'senior' is recommended.

Is it possible to live to be 120 years \& still be healthy?

The second half of the 20th century has seen a 20-year increase in mean life expectancy and, according to the forecasts, by 2050 this figure will have risen by another 10 years [4]. A particular definition of aging might be $\mathrm{H}$ ayflick's [5]:

"After performing the miracles that take us from conception to birth, and then to sexual maturation and adulthood, natural selection was unable to favor the development of a more lementary mechanism that would simply maintain those earlier miracles forever; the manifestations of this failure are called aging". 
Thus, as aging is a stochastic process that occurs systemically after reproductive maturity in animals that reach a fixed size in adulthood, $\mathrm{H}$ ayflick claims that the term 'anti-aging' is an oxymoron [1]. This term becomes irrelevant when it is used to describe delaying, preventing or resolving age-associated diseases [1]. As there is no generally accepted definition of aging or precise markers for measuring its rate of change, no action can be taken against the aging process [1]. So can anti-aging medicine be considered a legitimate science?

'The concept of suc cessful aging includes matters of dignity, a utonomy, social involvement and the absence of suffering, but not necessa rily the absence of sickness and dependence, which constitute an inevitable part of aging'

Cicconetti et al. claimed that longevity in centenarians is not an exceptional phenomenon, but is normal, and it is likely that all of us could diea natural death at the age of 120 years [6]. U nfortunately, in the past, individuals of great age have depended almost entirely on other people, even when they have adapted to circumstances and maintained a positive attitude to life and good social and family relations [7].

Q uality of life should be kept high; nobody would wish to live to 120 years unless they can remain self-sufficient. Perhaps this is the challenge for anti-aging medicine: to help humans stay healthy and self-sufficient for most of their lives, then experience a relatively rapid terminal decline. This might be considered an optimistic target for aging, but longevity without quality of life would be an unpleasant burden rather than a prize [8].

\section{Is being healthy synonymous with successful aging?}

D ealing with the changing patterns of aging will therefore be one of the great challenges of the twenty first century. That is why a priority of future research on aging should be to lay the foundations for a glorious period of successful aging [8] that we would all unquestionably want to achieve. But is aging an illness or a physiological part of life? In some academic circles, aging is seen as a disease, but this is not true (although for many it coincides with a 'collection' of diseases that lead to disability and progressive dependence on others).
We do not go to the emergency room because our hair is turning gray, our skin has wrinkled, our reactions have slowed, we have experienced some short-term memory loss, the strength of our grip has declined or we have become short-sighted or hard of hearing [1]. We have to distinguish between aging phenomena and age-related diseases: there can be aging without disease, so we cannot classify aging as part of any group of diseases.

Can we say that healthy aging is the same as successful aging?

To achieve the goal of successful aging, it is indispensable to have a better understanding of the 'reasons' for aging. Although numerous theories have been put forward to date, (more than 300 in fact, according to M edvedev [9]), no sure answer has been provided to the eternal questions posed by mankind: "Why am I aging? What must I do to avoid aging?". Unfortunately there are no clear answers for the immediate future either. Since the answers to these questions are not easy - health being the main (but not the only) factor involved in successful aging - other important factors need to be considered, as suggested in the Appendix

Try to imagine a healthy 80-year-old man with no diseases, who practices sport and drives a car, but who suffers as a result of bereavement, forced retirement, nostalgia for his job, depression, thoughts of death and other reasons. Compare him with the case of a disabled, wheelchairbound 80-year-old who plays the piano, gives concerts, wins the applause of his audience and feels gratified and satified.

Which of the two previous cases fits the cate gory of successful aging, the self-sufficient old and healthy person who is dissatisfied with life, or the one who is not self-sufficient but finds life gratifying? It is possible to age without becoming old, because elderly people can enjoy life even if they are disabled. The concept of successful aging includes matters of dignity, autonomy, social involvement and the absence of suffering, but not necessarily the absence of sickness and dependence, which constitute an inevitable part of aging [8].

\section{What exactly do we mean by \\ successful aging?}

What it means to age succesffully is still being debated. When asked, "H ow do human beings age successfully?", Rowe and Kahn said that succesfful aging is the ability to maintain a low risk 
of disease, high mental and physical functioning, and an active involvement in life [10]. But if successful aging is defined as an optimal state of overall functioning and wellbeing, there will be few people in the world who meet Rowe and Kahn's criteria.

'Qua lity of life should be kept high; nobody would wish to live to 120 years unless they can rema in self-suffic ient.'

C an we say that the celebrated case of $M$ adame Jeanne Calment of France, who died on August 4, 1997 at the age of 122, was a case of successful aging? W idowed at the age of 65 years, her only daughter died aged 37 years old and her only grandson was killed in a road accident when Calment was aged 88 years. Suddenly, she was alone. W hen she was aged 90 years, she sold her home and went into a nursing home. She outlived all the people she knew and in the last period of her life she was confined to a wheelchair, blind and almost totally deaf. So longevity is not the only feature of successful aging.

Getting old means acquiring disabilities sooner or later, so you are not the same person any more - you are old. This is an inescapable truth. In a recently published book based on their long and healthy family life experiences, Lazarus and Lazarus provide eight principles for coping with aging [11]. We have selected just four of them, which we feel are relevant for successful aging, that is, awareness of reality, commitment to an aim, networking with others and the protection of self-esteem. Lessons can be learned from the lifestyles of people who have been able to become role models for a long and successful life.

\section{Research evidence}

Research evidence indicates that symptoms of chronic disease in advanced life can be attributed to lifestyle choices involving diet, weight control, physical activity, smoking and alcohol intake. In this section, we wish to add first-hand experience of our research on the health of the elderly, and consequently on the aging process. EM Inelmen author was involved in a Europe-wide research program on the lifestyle (nutrition, physical activity and health status) of elderly people, named the Survey in Europe on Nutrition and the Elderly: a Concerted Action (SENECA) study, which prompted much discussion of the concept of healthy aging. A brief summary of the findings is given in the following sections.
Scope of research

It is important to study the factors that modulate aging, among which nutrition seems to have a very important effect on the state of health and quality of life of elderly people. The aim of this longitudinal study (1988/1989-1999) was thus to identify dietary and lifestyle factors that contribute to healthy aging [12].

Eating habits \& health

$N$ utrition is an important lifestyle factor contributing to health and functional ability. Dietary intake and nutritional status were assessed at the Italian center of the SEN ECA study (in Padova) on a random sample of 190 Italians (aged 70-75 years) [13]. The aim was to assess the adequacy of their diet by evaluating food intake, biochemical and anthropometric measures of nutritional status, and dietary characteristics of this Italian elderly population.

The general questionnaire included 89 items on sociodemographic situation, economic status, lifestyle, social activity, health status, self-reported health status, drug consumption, activities of daily living, physical activity and dietary habits. The chronic pathologies reported by the elderly were numerous: mainly osteoarthritis, especially in women $(49.5 \%)$, followed by hypertension and respiratory diseases and, in men, ischemic heart disease.

A randomly selected sample (such as the one considered here) is needed to identify the real dietary patterns in the elderly, so we also included people with aging-related social, clinical and disability problems, which can affect people's eating habits. We analyzed the composition of these people's diet, which had the typical features of the classic M editerranean diet.

Although the calcium intake was low, we concluded that the general nutritional status of our sample was fairly good. M ost people were able to get around outdoors and they reported a good opinion of their own state of health, despite a high prevalence of chronic diseases. Perhaps seniors view succesfful aging as a process of adaptation rather than a state of being [14].

\section{Results}

From the SENECA study as a whole (involving 2586 elderly people born between 1913 and 1918 and living in 19 towns in 12 European countries), it emerged that diet, physical activity and smoking habits correlated with survival and health status. A healthy lifestyle not only correlates with a better chance of survival, but also 
delays the deterioration in the person's state of health by comparison with unhealthy types of behavior. These results emphasize the importance of a healthy lifestyle, including multiple lifestyle factors, and its maintenance with advancing age [15].

\section{Lessons learned}

This study was very important in terms of defining 'healthy' elderly: health indicators (adequate dietary patterns, physical activity, no smoking and no excessive alcohol intake) are undoubtedly the main (but not the only) basics of succesfful aging. Healthy foods should be widely available, and healthy dietary patterns, with more fresh fruit and vegetables and less meat, salt and simple sugars (the so-called $M$ editerranean diet), should be promoted throughout our lives. However, further longitudinal studies are needed to correlate nutrient intake with anthropometric and body composition and health indicators.

In our Italian study, although the elderly suffered from numerous chronic diseases, they reported being in 'good health'. This paradox might be the result of their capacity to adapt or of a misconception of reality in the geriatric population. How elderly people see themselves depends on their degree of self-sufficiency, that is, their ability to remain capable of performing the activities of daily living. This was confirmed by the large percentage of our subjects who were physically quite active on a daily basis (e.g., walking, riding a bicycle and so on).

The low participation in community organizations might be related to the fact that elderly people in cities (such as Padova) are poorly motivated and paradoxically live more al one than elderly people in the country, who see more of their friends and neighbors. We have to draw from the 'perceptions' of the elderly, which can help us to define successful aging, rather than focus on medical concerns (chronic diseases). In this light, an elderly person who suffers from a chronic disease but remains active and satisfied with life can be defined as aging successfully.

\section{Future perspective}

The central aim of this article is to find evidence to identify the real meaning of successful aging. We need to reconsider our attitude to aging and the elderly. In future, multicenter research needs to be conducted on the satisfaction of the elderly in different settings (e.g., at home or in nursing homes, senior centers or other types of institution). Life expectancy is rising, but unfortunately the quality of life in old age is not.

We are not yet ready to cope with the elderly of the next 20-30 years. What are we doing, and what are we expected to do, for them? We have outlined some indicators for 'Aging without growing old' (Appendix), which could be taken up in future studies. Epidemiological studies show how important some variables are (e.g., weight control, exercise, nutrition, not smoking and moderate alcohol intake) in improving quality of life in older age. Undoubtedly, increasing the amount of physical exercise and ensuring an adequate diet can be effective in preventing or delaying chronic diseases, and improving musculoskeletal and cardiovascular functioning.

Future gerontological research should consider the heterogeneity of geriatric populations. $M$ ore debate needs to focus on the core meaning of successful aging, because this term has been used arbitrarily in the past. $N$ evertheless, being active seems to be a central element of successful aging.

If we are not destined to be immortal, as we would probably all like to be, is it really necessary to search for all sorts of ingenious ways to conceal the aging of our faces and bodies? Shouldn't we begin to accept this period as a 'golden' rather than as a 'gray' part of our life, and see it as a productive and creative time?

'...further long itud inal studies a re needed to correlate nutrient intake with anthropometric and body composition, and health indic ators.'

We have to enjoy aging, continuing to make plans for the future, as we know that our real age is not the chronological one, but the age we feel. The phenomenon of an increase in life-span is imposing a significant challenge for many sciences (biology, sociology, psychology, economics, policy and medicine), so gerontology needs to become multidisciplinary and expand its horizons to successful aging, even though there is no agreement as to the related nomenclature, definition and criteria. Nowadays, research is performed more on diseases and disabilities.

Studying people who stay healthy in advanced age can help us to promote healthcare activities and develop guidelines for healthy aging. Fortunately, health promotion and disease prevention are becoming important topics today in the care 
of the elderly; work on 'aging research' is increasing significantly. Nevertheless, we have to do more and more in this field because there is still little interest in studying individuals who have been lucky enough to remain free of disease.

To mitigate the negative effects of aging on elderly people, healthcare professionals have to help governments and nongovernmental organizations to implement policies and programs. H ow can medicine support healthy aging? The management of successful aging is possibly more of a sociological issue than a medical one. That is why the science of aging should be multidisciplinary. 0 ur goal should be to find strategies. For example, senior centers can serve as important meeting places where elderly people can take part in social activities, such as the arts, conferences, cinema, music, computers and traveling.

Educational opportunities designed for seniors have recently been developed in Western countries. In Italy, for example, we have open universities running courses for the 'third age'. Giving seniors the opportunity to do voluntary work is also a good way to keep them occupied and useful to society. Families and caregivers are encouraged to participate in health-promotion schemes. The problem now could well be that there will be too many baby boomers, people born soon after World War II, and too few resources for them.

'...a consensus among the political

forces must be encouraged in order to give every citizen the chance of an a dequate lifestyle.'

To develop such resources should be one of our strategies for successful aging, bearing in mind that these resources may need to be handled differently, as the elderly of the future will not be the same as those of today. Particular attention needs to be given to the elderly women of tomorrow, because of changes in their behavior patterns and lifestyle over the past few decades. Women are likely to have worked more outside the home, smoked more, drunk more and experienced the stress of a dual role in society, inside and outside the home.

\section{Conclusion}

The point we wish to make in this editorial is that it is essential to discuss the issues relating to successful aging, and to propose new policies to implement in public-health circles. First of all, we have to abandon the idea that old age is synonymous with illness, disability, lack of memory or vitality, sadness, depression, loneliness, unproductivity, inability to learn and change and helplessness. Fortunately, succesful aging is becoming widespread: people are healthier, more active and better educated than before. The secret to successful aging seems to be not just a matter of fortuitous genetic matches, but also of lifestyle, cultural and social experiences and social conditions [15].

We are soon expecting to see a generation of successfully aging elderly people. A review on the historical perspectives of aging will point to new issues [16]. To find adequate answers to the crucial social questions, a consensus among the political forces must be encouraged in order to give every citizen the chance of an adequate lifestyle. However, there are still many other questions that need to be tackled, including:

- What are the differences between the elderly born at the beginning of the twentieth century and the baby boomers?

- What are the prospects for the elderly, some of whom are now taking early retirement, in the future?

We have to remember that humans cannot, and never will be, able to live forever. But can we age successfully and then die unsuccessfully, as Jeanne Calment did (disabled, blind and deaf )? O r can we die 'healthy'? 'H ealthy death' or 'successful death': are these oxymorons as 'anti-aging' is? Is 'successful death' a part of 'succesful aging'? There will always be new questions seeking new answers. Future research will probably provide further evidence on this complex topic.

We can conclude by saying that the new motto might be: "Aging without growing old: adding more years of self-sufficient living in our own homes and compressing morbidity into very old age, is one of the greatest challenges for the new millennium."

Financial \& competing interests dislosure

The authors have no relevant financial interests including employment, consultancies, honoraria, stock ownership or options, expert testimony, grants or patents received or pending, or royalties related to this manuscript.

$\mathrm{No}$ writing assistance was utilized in the production of this manuscript. 


\section{Bibliography}

1. H ayflick L: 'Anti-aging' is an oxymoron. J. Gerontol. Biol. Sci. 59(6), 573-578 (2004).

2. N euhaus RH, $\mathrm{N}$ euhaus $\mathrm{RH}$ : Succesful Aging. John Wiley, N Y, U SA, 233-239 (1982).

3. Sirtori CR, C alabresi L, Franceschini G : $C$ ardiovascular status of carriers of the apolipoprotein $\mathrm{A}-\mathrm{I}_{\text {M ilano }}$ mutant: the Limone sul Garda Study. Circulation 103, 1949-1954 (2001).

4. U nited N ations: Report of the Second World Assembly on Aging. M adrid, Spain, 8-12 April 2002.

5. H ayflick L: $\mathrm{H}$ ow and why we age. Exp. Gerontol. 33(7-8), 639-653 (1998).

6. Cicconetti $P$, Tafaro $L$, Tedeschi $G$ et al.: Lifestyle and cardiovascular aging in centenarians. Arch. Gerontol. Geriatr. 8(Suppl.), 93-98 (2002).
7. Dello Buono M, Urciuoli O, de Leo D: Q uality of life and longevity: a study of centenarians. Age Ageing 27(2), 207-216 (1998).

8. Inelmen EM , Sergi $G$, Enzi $G$, Toffanello ED, Coin A, Inelmen E: $\mathrm{N}$ ew approach to gerontology: building up 'successful aging' conditions. Aging Clin. Exp. Res. 19(2), 160-164 (2007).

9. M edvedev ZA: An attempt at a rational classification of theories of aging. Biol. Rev. 65(2), 375-398 (1990).

10. Rowe JW, Kahn RL: Successful aging. Aging Clin. Exp. Res. 10(2), 142-144 (1998).

11. Lazarus RS, Lazarus $N$ : C oping W ith Aging O xford University Press, 0 xford, UK 215-221 (2006).

12. H aveman-N ies A: D ietary Q uality, Lifestyle Factors and $\mathrm{H}$ ealthy Aging in Europe D issertation. Wageningen U niversity, The $N$ etherlands (2001).
13. Inelmen $E M$, Jimenez $G F, G$ atto $M R A$ et al.: D ietary intake and nutritional status in Italian elderly subjects. J. N utr. H ealth Aging 4(2), 91-101 (2000).

14. Baltes PB, Smith J: N ew frontiers in the future of aging: from successful aging of the young old to the dilemmas of the fourth age. Gerontology 49(2), 123-135 (2003).

15. H aveman-N ies A, de Groot LC, van Staveren W: D ietary quality, lifestyle factors and healthy ageing in Europe: the SEN ECA study. Age Ageing 32(4), 427-434 (2003).

16. Thornton JE: M yths of aging or ageist stereotypes. Educ. Gerontol. 28, 301-312 (2002).

\section{Appendix}

\section{'Aging without growing old'; some indicators}

- To be free of disease

- To have access to healthcare facilities

- To believe that poor health is not an unavoidable consequence of aging

- To have regular physical activity (walking, shopping, riding the bicycle and so on)

- To stay mobile and competent in all activities of daily living

- To control body weight (by healthy eating habits)

- No cigarette smoking

- No alcohol abuse

- To preserve hearing and eyesight

- To be able to go out alone

- To continue life as in earlier adulthood

- To be in healthy mental condition

- To maintain youthful intellectual stimulation

- To have a positive view of life

- To live at home, not in gloomy nursing homes

- To have interests (arts, lectures, gardening, cinema, theatre, dance, conferences, tourism, computers, writing, cooking and so on)

- To continue learning (i.e., university for the third age)

- To have strong social networks (neighborhood included)

- To have financial security

- To make plans for the future

- To have self-esteem, even if you live in a society obsessed with youthfulness

- To take care of yourself and stay in good physical shape

- To be sure that 'somebody' (no matter who) can help in case of need

- To maintain a safe environment

- To be aware of and not be discouraged by aging

- Not to be afraid of death or think about dying

- To be satisfied with yourself

- To be able to cope with stressful life events

- To preserve your social role

- To be able to drive a car and stay independent

- To see aging as a useful and enjoyable journey

- To stay involved in life

- To have the chance to carry on working in your job after retirement (if you wish)

- To believe that serenity and happiness can be achieved despite age-related problems 